\title{
Flow Injection On-Line Solid Phase Extraction \\ Coupled with Inductively Coupled Plasma \\ Mass Spectrometry for Determination \\ of (Ultra)Trace Rare Earth Elements \\ in Environmental Materials Using \\ Maleic Acid Grafted Polytetrafluoroethylene \\ Fibers as Sorbent
}

\author{
Zhao-Hui Wang, Xiu-Ping Yan, Zhi-Peng Wang, Zheng-Pu Zhang, \\ and Li-Wen Liu \\ Key Laboratory of Functional Polymer Materials, Ministry of Education, Research Center for Analytical \\ Sciences, College of Chemistry, Nankai University, Tianjin, China
}

\begin{abstract}
A new sorbent, maleic acid grafted polytetrafluoroethylene fiber (MA-PTFE), was prepared and evaluated for on-line solid-phase extraction coupled with inductively coupled plasma mass spectrometry (ICP-MS) for fast, selective, and sensitive determination of (ultra)trace rare earth elements (REEs) in environmental samples. The REEs in aqueous samples at $\mathrm{pH}=3.0$ were selectively extracted onto a microcolumn packed with the MA-PTFE fiber, and the adsorbed REEs were subsequently eluted on-line with 0.9 mol $1^{-1} \mathrm{HNO}_{3}$ for ICP-MS determination. The new sorbent extraction system allows effective preconcentration and separation of the REEs from the major matrix constituents of alkali and alkali earth elements, particularly their separation from barium that produces considerable isobaric interferences of ${ }^{134} \mathrm{Ba}^{16} \mathrm{O}^{1} \mathrm{H}^{+},{ }^{135} \mathrm{Ba}^{16} \mathrm{O}^{+},{ }^{136} \mathrm{Ba}^{16} \mathrm{O}^{1} \mathrm{H}^{+}$, and ${ }^{137} \mathrm{Ba}^{16} \mathrm{O}^{+}$on ${ }^{151} \mathrm{Eu}^{+}$and ${ }^{153} \mathrm{Eu}^{+}$. With the use of a

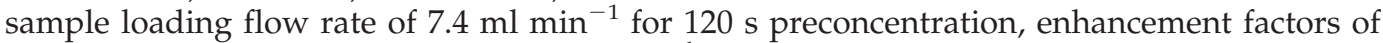
69-97 and detection limits (3s) of 1-20 pg $1^{-1}$ were achieved at a sample throughput of 22

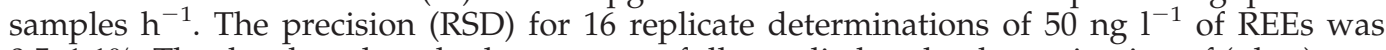
$0.5-1.1 \%$. The developed method was successfully applied to the determination of (ultra)trace REEs in sediment, soil, and seawater samples. (J Am Soc Mass Spectrom 2006, 17, 1258-1264) (C) 2006 American Society for Mass Spectrometry
\end{abstract}

$\mathrm{E}$ nvironmental effects of rare earth elements (REEs), namely lanthanides, have become of great concern owing to their increasing use in industrial products and agriculture [1,2]. REEs also serve as analogs for the actinide elements (Am and $\mathrm{Cm}$ ), such that the accurate determination of REEs at low levels is likewise important for predicting the behavior of the radioactive actinides in future radioactive waste repositories [3]. Therefore, it is essential to establish a reliable and sensitive analytical method to determine REEs in environmental materials and, furthermore, to understand how REEs migrate and transfer in the ecological environmental system, which could help in the study of the physiological

Published online June 30, 2006

Address reprint requests to Dr. X.-P. Yan, College of Chemistry, Nankai University, 94 Weijin Road, Tianjin 300071, China. E-mail: xpyan@nankai.edu.cn actions of REEs and in the prediction of any potential environmental effects.

Inductively coupled plasma mass spectrometry (ICPMS) has definitely emerged as a powerful technique for element determination owing to its high sensitivity, low detection limits, linear dynamic range of up to nine orders of magnitude, and its capability to measure multi-element and isotope ratio with relative simple spectra interferences [4-6]. However, its application to direct determination of ultratrace REEs in complicated environmental samples is quite limited because highly saline samples can cause both isobaric interferences and matrix effects [7]. Especially, due to significant isobaric interferences $\left({ }^{134} \mathrm{Ba}^{16} \mathrm{O}^{1} \mathrm{H}^{+},{ }^{135} \mathrm{Ba}^{16} \mathrm{O}^{+},{ }^{136} \mathrm{Ba}^{16} \mathrm{O}^{1} \mathrm{H}^{+}\right.$, ${ }^{137} \mathrm{Ba}^{16} \mathrm{O}^{+}$) on ${ }^{151} \mathrm{Eu}^{+}$and ${ }^{153} \mathrm{Eu}^{+}$, one of the low abundance REEs that may fractionate from neighboring REEs in natural systems from changes in oxidation state, good separation of REEs from Ba is a prerequisite for accurate ICP-MS determination of REEs in samples with high ratios of Ba to REEs $[8,9]$. 
Both off-line (batch-wise mode) [10-16] and online [16-19] preconcentration and separation procedures have been developed for ICP-MS determination of (ultra)trace REEs. Compared with those offline operation counterparts, flow injection (FI) on-line separation and preconcentration systems provide many advantages, such as little risk of analyte loss and contamination, potential improvement of selectivity through kinetic discrimination under chemically nonequilibrated conditions, lower detection limits, improved precision, reduced sample and reagent consumption and waste production, high efficiency, and automation $[16,20]$. The most widely used techniques for the on-line separation and preconcentration of trace REEs are those based on solid-phase extraction (SPE) [11, 17-19] due to the advantages of easiness to couple with ICP-MS, rapid phase separation, high enrichment factor, sampling in the field, no formation of emulsion, safety with respect to hazardous samples, low cost, and flexibility [20].

Development of new sorbents with good ability to separate REEs from the major matrix constituents-alkali and alkali earth elements, especially from barium, is of particular significance for reliable determination of ultratrace REEs in environmental samples by FI on-line solidphase extraction coupled with ICP-MS. In addition, to allow smooth running of the FI on-line solid-phase extraction preconcentration system, some special requirements for the sorbent materials should be met, such as negligible swelling capacity to resist swelling and shrinking with change in $\mathrm{pH}$ and/or solvent conditions, strong mechanical stability to withstand high linear flow rates, and high chemical resistibility to endure harsh conditions [21]. The chemical inertness, elevated resistibility, low friction coefficient, and good swelling resistance of polytetrafluoroethylene (PTFE) make it very attractive as the substrate for the sorbent for FI on-line solid-phase extraction preconcentration systems [22].

The aim of this work is to prepare a new sorbent, maleic acid grafted PTFE fibers (MA-PTFE), and to evaluate it as sorbent for FI on-line, solid-phase extraction coupled with ICP-MS for determination of (ultra)trace REEs in environmental samples.

\section{Experimental}

\section{Instrumentation}

A Model X 7 ICP-MS system equipped with a glass concentric nebulizer and PlasmaLab software (Thermo Elemental, Waltham, MA) was used throughout. The instrument was optimized daily and operated as recommended by the manufacturer to minimize isobaric interferences of the light REE (La$\mathrm{Gd}$ ) oxides on the heavy REEs (Tb-Lu). The nebulizer gas flow rate was adjusted so that the $\mathrm{CeO} / \mathrm{Ce}$ ratio and $\mathrm{BaO} / \mathrm{Ba}$ were less than $3 \%$. The "TRA profile mode" data collection mode in the PlasmaLab software was used to monitor the signals of the 14 REEs.
Table 1. Operating conditions and mass spectrometer settings of the X-series ICP-MS for the determination of REEs using online solid phase extraction

\begin{tabular}{|c|c|}
\hline Parameter & Value \\
\hline RF power & $1250 \mathrm{~W}$ \\
\hline Coolant gas flow rate (Ar) & $13.01 \mathrm{~min}^{-1}$ \\
\hline Carrier gas flow rate (Ar) & $0.77 \mathrm{I} \mathrm{min}^{-1}$ \\
\hline Nebulizer gas flow rate (Ar) & $0.86 \mathrm{I} \mathrm{min}^{-1}$ \\
\hline Sampling depth & $6.0 \mathrm{~mm}$ \\
\hline Sampler & Nickel,1.1 mm orifice \\
\hline Skimmer & Nickel, $0.75 \mathrm{~mm}$ orifice \\
\hline \multicolumn{2}{|l|}{ Ion lenses } \\
\hline Extraction & -671 \\
\hline Lens 1 & 1.0 \\
\hline Lens 2 & -25.1 \\
\hline Lens 3 & -189.8 \\
\hline \multicolumn{2}{|l|}{ Data acquisition } \\
\hline Scanning mode & Profile TRA \\
\hline Dwell time & $10 \mathrm{~ms}$ \\
\hline Integration mode & Peak area \\
\hline \multicolumn{2}{|l|}{ Detector } \\
\hline PC detector & $2884 \mathrm{~V}$ \\
\hline Analog & $1860 \mathrm{~V}$ \\
\hline
\end{tabular}

Peak area was used for quantification. The operating parameters of the ICP-MS system used in this work are given in Table 1.

A model FIA-3110 flow injection analyzer (Vital Instrumental, Beijing, China) was employed for the on-line solid-phase extraction of REEs. Only one pump of the analyzer was employed to propel the sample solution to complete on-line solid-phase extraction. The Peripump of the ICP-MS instrument (Thermo Elemental, Waltham, MA) was employed and controlled automatically by PlasmaLab software. Approximately $40 \mathrm{~cm}$ of $0.5 \mathrm{~mm}$ i.d. PTFE tubing was used to connect the valve to the Meinhard nebulizer (Grass Expansion Inc., Pocasset, MA) of the ICP-MS instrument. The manifold used for on-line solid-phase extraction of REEs is shown in Figure 1. Tygon peristaltic pump tubing (ISMATEC SA, Glattbrugg, Switzerland) was employed to propel the sample and reagents.

\section{Reagents}

Concentrated $\mathrm{HNO}_{3}, \mathrm{HF}$, and $\mathrm{NH}_{3} \cdot \mathrm{H}_{2} \mathrm{O}$ solutions were of ultrapure grade (BV-III, Beijing Institute of Chemical Reagent, Beijing, China). Doubly deionized water (DDW, $18.2 \mathrm{M} \Omega \mathrm{cm}^{-1}$ ) obtained from a WaterPro water system (Labconco Corporation, Kansas City, MO) was used throughout. Single element stock solutions of REEs at 1000 $\mathrm{mg} \mathrm{l}^{-1}$ and $\mathrm{Ba}, \mathrm{Mg}$ at $100 \mathrm{mg} \mathrm{l^{-1 }}$ were obtained from the National Research Center for Certified Reference Materials (NRCCRM, Beijing, China). Stock multi-REEs solution of multi-REEs at $10 \mathrm{mg} \mathrm{l}^{-1}$ of each element in $2 \% \mathrm{vol} / \mathrm{vol}$ $\mathrm{HNO}_{3}$ was prepared by diluting the single element stock solutions. Working multi-REEs solutions were prepared by series dilution of the stock multi-REEs solution immediately before use. All other reagents were of at least analytical grade. All cleaning operations and sample and 


\section{(a) Sample loading}

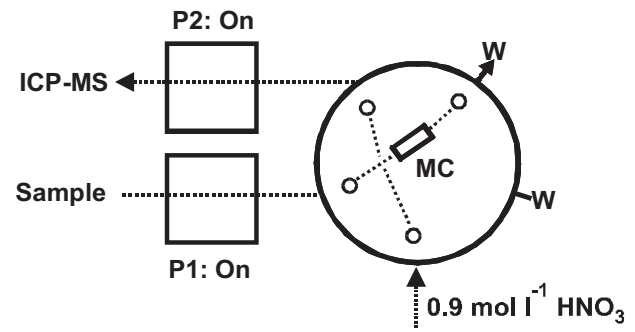

(b) Elution

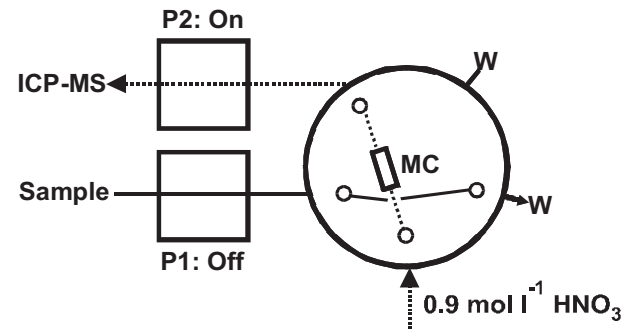

Figure 1. FI manifold of the developed on-line solid-phase extraction for ICP-MS determination of ultratrace REEs. P1 and P2, peristaltic pumps; $\mathrm{MC}$, microcolumn; valve position (a) fill; (b) injection; W, waste.

reagent chemistries were carried out in a class 100 clean bench.

\section{Synthesis of MA-PTFE}

A direct irradiation grafting method [23, 24] was employed to prepare the maleic acid grafted PTFE fibers (20 $\mu \mathrm{m}$ in diameter, Tongchuang Co., Beijing, China). About $150 \mathrm{~g}$ of maleic acid was dissolved in $350 \mathrm{ml}$ acetone to produce $30 \%$ acetone solution, to which $8 \mathrm{~g}$ of cleaned PTFE fibers and $1 \mathrm{~g}$ of azo-bis-isobutyronitrile (Shanghai Sihewei Chemicals, Shanghai, China) were added as initiator. The mixture was degassed by bubbling with a high purity nitrogen flow for about $20 \mathrm{~min}$, sealed, and subjected

to

${ }^{60} \mathrm{Co}$ irradiation at a dose rate of $0.8 \mathrm{kGy} \mathrm{h}^{-1}$ for $48 \mathrm{~h}$. After irradiation the grafted PTFE fibers was filtered, repeatedly washed with $1 \mathrm{~mol} \mathrm{l}^{-1} \mathrm{NaOH}$, DDW, $1 \mathrm{~mol} 1^{-1} \mathrm{HCl}$, and DDW three times to remove unreacted monomers and homopolymers, and dipped into $1 \mathrm{~mol} \mathrm{l}^{-1} \mathrm{HCl}$ for $24 \mathrm{~h}$ to reduce anhydride to carboxylic groups (Figure 2). The resulting grafted fiber was filtered, washed with DDW to complete removal of the residual acid, then with copious amount of acetone, and dried in a vacuum oven at $50{ }^{\circ} \mathrm{C}$ for $48 \mathrm{~h}$.

\section{FI On-Line Solid Phase Extraction for ICP-MS determination of REES}

The microcolumn for on-line solid-phase extraction was made from a PTFE tube with an effective length of $2 \mathrm{~cm}$ and an i.d. of $3 \mathrm{~mm}$. The MA-PTFE fibers with a length of $\sim 2 \mathrm{~cm}$ were random-packed tightly onto the microcolumn like a cotton ball. The fibers were held in place by two end-screw connectors. The mass of the fibers tightly filled into the column was measured to be 0.1633 g. The microcolumn was sequentially washed with DDW, $1 \mathrm{~mol} \mathrm{l}^{-1} \mathrm{HNO}_{3}$, and DDW until the effluent contained no REE and other ions.

Figure 1 shows the FI manifold for the operation sequence of the FI on-line solid-phase extraction coupled with ICP-MS. In the prefill step (Figure 1b), the microcolumn was washed with 0.9 mol $1^{-1} \mathrm{HNO}_{3}$ and the tubing was flushed with sample solution for $10 \mathrm{~s}$. This prefill stage was used only when a new sample was introduced, but omitted for replicate preconcentrations of the same sample. In Step 1, the valve was in the "fill" position, the sample solution was loaded onto the packed column at flow rate of $7.4 \mathrm{ml} \mathrm{min}^{-1}$ for $120 \mathrm{~s}$ by pump 1; meanwhile 0.9 mol $1^{-1} \mathrm{HNO}_{3}$ was introduced into the ICP-MS at $0.5 \mathrm{ml} \mathrm{min}^{-1}$ for baseline. In Step 2, the injector valve was turned to the "inject" position and pump 1 stopped so that 0.9 mol $1^{-1} \mathrm{HNO}_{3}$ was introduced at a flow rate of $0.5 \mathrm{ml} \mathrm{min}{ }^{-1}$ for $35 \mathrm{~s}$ to elute the adsorbed REEs into the ICP-MS for determination. The total time for one replicate on-line preconcentration and analysis was $165 \mathrm{~s}$ including $120 \mathrm{~s}$ sample loading time.

\section{Samples}

The polyethylene bottles used for sampling water were precleaned with detergent, DDW, dilute $\mathrm{HNO}_{3}$, and DDW, respectively. Seawater samples were collected from Tianjin, Dalian, and Qingdao, China. River water samples were obtained from Haihe River (Tianjin, China), Jinghang Canal (Cangzhou, China), and Weijin River (Tianjin, China). All samples were filtered through $0.45-\mu \mathrm{m}$ super filters, acidified to $\mathrm{pH}=3.0$, and stored at $4{ }^{\circ} \mathrm{C}$ or measured at once.

Three certified reference materials (CRMs) from NRCCRM, i.e., GBW 07312 (sediment), GBW 07313 (marine sediment), and GBW 07405 (soil), were analyzed to check the accuracy of the developed on-line solid-phase extraction coupled with ICP-MS for determination of REEs in environmental samples.

\section{Sample Digestion}

About $0.1 \mathrm{~g}$ of the CRMs were thoroughly mixed with 4 $\mathrm{ml}$ of $65 \% \mathrm{HNO}_{3}, 1 \mathrm{ml} 30 \% \mathrm{H}_{2} \mathrm{O}_{2}$, and $1 \mathrm{ml}$ of $40 \% \mathrm{HF}$

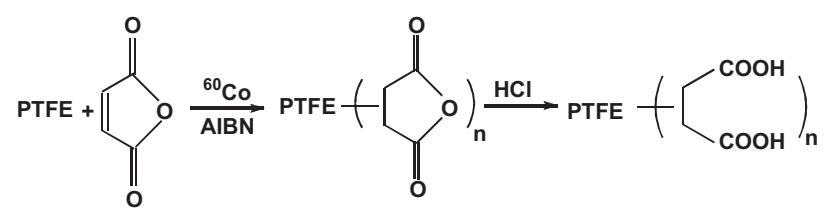

Figure 2. Schematic representation of the reaction between PTFE and maleic anhydride. 


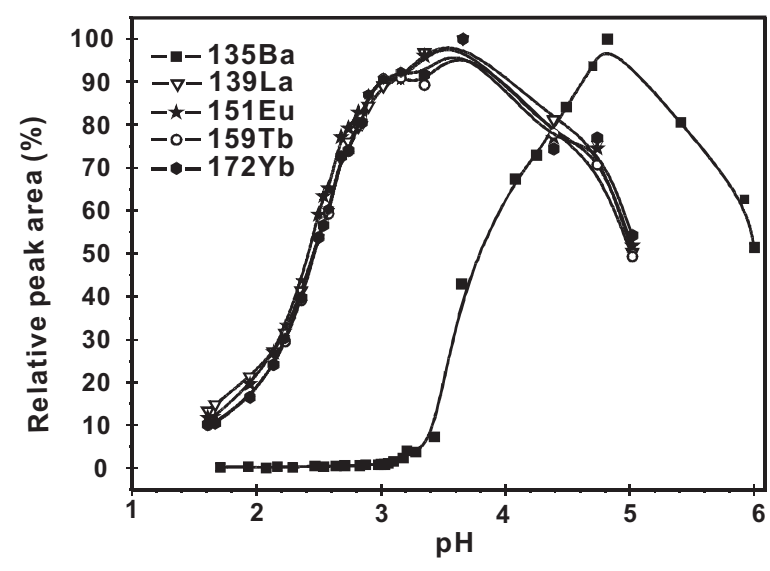

Figure 3. Effect of the $\mathrm{pH}$ of sample solution on the on-line solid-phase extraction of trace REEs and $\mathrm{Ba}(\mathrm{II})$.

in a PTFE pressure vessel. The PTFE vessel was closed and left to stand overnight. A microwave program (EPA 0512) was then applied to the vessel for sample digestion. After the PTFE vessel cooled down to room temperature, $0.5 \mathrm{ml}$ of $40 \% \mathrm{HF}$ was added and the EPA 0512 program was applied again. Once the PTFE vessel cooled down to room temperature, $0.5 \mathrm{ml}$ of $30 \% \mathrm{H}_{2} \mathrm{O}_{2}$ was added to stand for $1 \mathrm{~h}$. Five $\mathrm{ml}$ of boric acid solution (5.00 g of $\mathrm{H}_{3} \mathrm{BO}_{3}$ in $100 \mathrm{ml}$ of DDW) was added to dissolve precipitated fluorides and EPA0512 was applied again [25]. The clear digests were diluted to 500 $\mathrm{ml}\left(\mathrm{pH}=3.0\right.$, adjusted with $5 \% \mathrm{vol} / \mathrm{vol} \mathrm{HNO}_{3}$ and diluted $\mathrm{NH}_{3} \cdot \mathrm{H}_{2} \mathrm{O}$ ). A blank solution was also prepared in parallel.

\section{Results and Discussion}

\section{Determination of the Content of Grafted Groups on the PTFE Fiber}

Quantification of the grafted groups was determined by an acid-base back titration method; $0.5 \mathrm{~g}$ of MA-PTFE was cut into mm-grade using a stainless scissors, and mixed with $20 \mathrm{ml}$ of $0.2 \mathrm{~mol} \mathrm{l}^{-1} \mathrm{NaOH}$ solution. After electro-magnetic stirring of the mixture for $3 \mathrm{~h}, 10 \mathrm{ml}$ of the supernatant was titrated with $0.2 \mathrm{~mol} \mathrm{l}^{-1} \mathrm{HCl}$. The content of the $-\mathrm{COOH}$ grafted on the PTFE fiber was determined to be $0.61 \mathrm{mmol} \mathrm{g}^{-1}$.

\section{Binding Capacity of the MA-PTFE Fibers}

The static binding capacity of the MA-PTFE fiber was determined for $\mathrm{La}$ (III) by a batch experiment. $100 \mathrm{mg}$ of the MA-PTFE fiber was equilibrated by shaking for $24 \mathrm{~h}$ in the excess $\mathrm{La}(\mathrm{III})$ solution $\left(50 \mathrm{ml}, 10 \mathrm{mg} \mathrm{l}^{-1}\right.$ ) at optimum adsorption $\mathrm{pH}=3.0$. Then, the MA-PTFE fiber was filtered off and the concentration of the remaining $\mathrm{La}$ (III) in the solution was determined by ICP-MS. The result of the static capacity for La was determined to be $0.31 \mathrm{mmol} \mathrm{g}^{-1}$.
The dynamic capacity of the MA-PTFE fibers was determined by passing $\mathrm{La}$ (III) solution at optimum $\mathrm{pH}$ through a cylindrically shaped PTFE microcolumn (2-cm long $\times 3-\mathrm{mm}$ i.d.) packed with $0.1633 \mathrm{~g}$ of the MA-PTFE fibers at a fixed flow rate until the concentration of the metal ions in the effluent was the same as in the influent. Successively fractions of $1 \mathrm{ml}$ effluent aliquots were collected, in which the concentration of $\mathrm{La}$ (III) was measured by ICP-MS. The dynamic binding capacity was then calculated according to Wang and Barnes [26].

The effect of sample flow-rate on the dynamic capacity of the MA-PTFE fibers was examined. No remarkable effect of sample flow-rate on the dynamic capacity was observed in a sample loading flow rate range of 1 to $3 \mathrm{ml} \mathrm{min}$. The dynamic capacity decreased as the sample flow-rate increased from 3 to $7 \mathrm{ml} \mathrm{min}^{-1}$. Further increase in sample loading flow rate resulted in more rapid decrease in dynamic capacity likely due to the limited retention kinetics and less contact time for retention.

\section{Development of an FI On-Line Solid-Phase Extraction Protocol of for ICP-MS Quantification of (Ultra)Trace REEs in Environmental Materials Using the MA-PTFE Fibers as Sorbent}

The effect of the $\mathrm{pH}$ of sample solution on the on-line solid-phase extraction of REEs was investigated from $\mathrm{pH}=1$ to 5. As shown in Figure 3, the optimum $\mathrm{pH}$ range for group REEs extraction was in a $\mathrm{pH}$ range of 2.8 to 3.6.

To evaluate the ability of the present FI on-line solid-phase extraction system to separate REES from $\mathrm{Ba}$, the $\mathrm{pH}$ dependence of the $\mathrm{Ba}(\mathrm{II})$ ion intensity was also examined (Figure 3). Ba(II) can not be preconcentrated below $\mathrm{pH}=3.1$, and the maximum Ba signal was observed between $\mathrm{pH}$ 4.7-5.0. Accordingly, the effect of $\mathrm{Ba}$ on the ICP-MS determination of Eu can be eliminated by controlling the $\mathrm{pH}$ of sample solution below 3.1.

To find the possibility for eliminating the effect of dissolved salts on the ICP-MS determination, the $\mathrm{pH}$ dependence of the on-line solid-phase extraction of $\mathrm{Na}(\mathrm{I})$ was investigated in a wide $\mathrm{pH}$ range of 1.5 to 10.9 under cool plasma conditions. It was found that the $\mathrm{Na}$ signal was at baseline level at $\mathrm{pH}=1.5-5.0$, and increased rapidly with further increase in $\mathrm{pH}$. Studies on the effect of the $\mathrm{pH}$ of sample solution on the on-line solid-phase extraction of $\mathrm{Mg}$ (II) under hot plasma conditions showed that the Mg signal was nearly at baseline level at $\mathrm{pH} \leq 4.5$, and reached maximum at $\mathrm{pH}$ $>10.6$. Under the condition of $\mathrm{pH} \leq 4.5$ the matrix interferences from the two main coexisting ions of $\mathrm{Na}(\mathrm{I})$ and $\mathrm{Mg}$ (II) in natural water, especially in seawater, can be eliminated. For selective group extraction of REEs and effective elimination of the interferences from $\mathrm{Ba}$ 
Table 2. Analytical figures of merit of the on-line solid phase extraction coupled with ICP-MS for determination of REEs under experimental conditions shown in Table 1

\begin{tabular}{|c|c|c|c|}
\hline Isotope & $\begin{array}{l}\text { Detection limit } \\
\qquad(3 s)^{\mathrm{a} /} / \mathrm{pg} \mathrm{I}^{-1}\end{array}$ & $\begin{array}{l}\text { Enhancement } \\
\text { factor }^{\mathrm{b}}\end{array}$ & $\begin{array}{c}\text { Precision } / \% \\
(\text { RSD, } n=16)^{\mathrm{c}}\end{array}$ \\
\hline${ }^{139} \mathrm{La}$ & 9 & 76 & 0.5 \\
\hline${ }^{140} \mathrm{Ce}$ & 20 & 75 & 0.5 \\
\hline${ }^{141} \mathrm{Pr}$ & 3 & 79 & 0.6 \\
\hline${ }^{145} \mathrm{Nd}$ & 16 & 81 & 1.0 \\
\hline${ }^{147} \mathrm{Sm}$ & 14 & 84 & 1.1 \\
\hline${ }^{151} \mathrm{Eu}$ & 13 & 85 & 0.7 \\
\hline${ }^{157} \mathrm{Gd}$ & 12 & 83 & 0.9 \\
\hline${ }^{159} \mathrm{~Tb}$ & 2 & 81 & 0.5 \\
\hline${ }^{161} \mathrm{Dy}$ & 4 & 79 & 0.6 \\
\hline${ }^{165} \mathrm{Ho}$ & 1 & 69 & 0.5 \\
\hline${ }^{166} \mathrm{Er}$ & 5 & 69 & 0.8 \\
\hline${ }^{169} \mathrm{Tm}$ & 2 & 97 & 0.5 \\
\hline${ }^{172} \mathrm{Yb}$ & 4 & 88 & 0.5 \\
\hline${ }^{175} \mathrm{Lu}$ & 1 & 80 & 0.5 \\
\hline
\end{tabular}

${ }^{a}$ Based on $3 s$ of 11 replicate determinations of the blank.

${ }^{b}$ Calculated as the ratio of the slope of the linear portion of the calibration curves after the on-line solid extraction to that without on-line solid extraction.

${ }^{\mathrm{c} B a s e d}$ on 16 replicate preconcentrations of $50 \mathrm{ng} \mathrm{I}^{-1}$ aqueous multielement standard.

and dissolved salts, the sample solution was adjusted to $\mathrm{pH}=3.0$.

The effect of sample loading flow rate on the FI on-line solid-phase extraction of $50 \mathrm{ng} 1^{-1}$ REEs and $\mathrm{Ba}(\mathrm{II})$ was examined at a sample $\mathrm{pH}=3.0$ with a sample loading time of $30 \mathrm{~s}$. The signal intensities of REEs increased almost linearly with sample loading flow rate from 2.7 to $7.4 \mathrm{ml} \mathrm{min}^{-1}$, then gradually leveled off with further increase in sample loading flow rate. However, the signal intensity of $\mathrm{Ba}$ was always at baseline level as sample loading flow rate increased

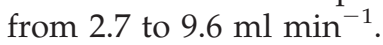

Studies of the effect of sample loading time on the on-line solid-phase extraction of $50 \mathrm{ng} \mathrm{1^{-1 }}$ REEs and $\mathrm{Ba}(\mathrm{II})$ at a sample $\mathrm{pH}=3.0$ with a sample loading flow rate of $7.4 \mathrm{ml} \mathrm{min}^{-1}$ showed that the signal intensity of each REE increased linearly as sample loading time increased up to $135 \mathrm{~s}$, after which the slope decreased gradually, whereas the Ba signal was still at baseline level and was not affected by the sample loading time. These results indicate that a higher enhancement factor for REEs could be achieved by properly increasing sample flow rate and/or sample loading time without increasing the interferences from Ba.

Dilute nitric acid was selected for on-line elution of the extracted REEs and transport of the analytes to the ICP-MS system, given its high efficiency for the analyte elution and its low background for ICP-MS analysis. The concentration and flow rate of the nitric acid solution for elution were optimized in light of sensitivity and precision; 0.9 mol $1^{-1}$ of $\mathrm{HNO}_{3}$ at a flow rate of $0.5 \mathrm{ml} \mathrm{min}{ }^{-1}$ was selected for elution to ensure good precision and to obtain reasonable sensitivity.

\section{Analytical Performance of the FI On-Line Solid- Phase Extraction Coupled with ICP-MS for (Ultra)Trace REEs Determination}

Table 2 summarizes the figures of merit of the on-line solid-phase extraction coupled with ICP-MS for simultaneous extraction and determination of 14 REEs under the conditions given in Table 1 . A comparison of the developed FI on-line solid-phase extraction preconcentration and separation system with other previous reported on-line solid-phase extraction preconcentration and separation systems [11, 17-19] for ICP-MS determination of REEs in terms of sample throughput, enhancement factor, detection limit, and precision is made in Table 3. Generally speaking, the developed on-line solid-phase extraction coupled with ICP-MS using the MA-PTFE fibers as sorbent offer lower detection limits, higher sample throughput, better precisions, and higher enhancement factors.

\section{Validation of the Developed Methodology}

Owing to the lack of seawater and natural water CRMs for REEs, the accuracy of the developed on-line solid-phase extraction coupled with ICP-MS for determination of (ultra)trace REEs in environmental materials was checked by analyzing a number of CRMs, GBW 07312 (sediment), GBW 07313 (marine sediment) and GBW 07405 (soil). The analytical results for the concentrations of REEs in these CRMs obtained by the developed on-line solid-phase extraction coupled with ICP-MS are compared with those certified in Table 4. Good agreement between the determined concentrations of REEs in these CRMs by

Table 3. Comparison of the developed on-line solid phase extraction system with previous on-line solid-phase extraction systems for ICP-MS determination of REEs

\begin{tabular}{|c|c|c|c|c|c|}
\hline Sorbent & $\begin{array}{c}\text { Sample } \\
\text { throughput } \\
\left(\text { samples } \mathrm{h}^{-1}\right)\end{array}$ & RSD (\%) & $\begin{array}{l}\text { Detection } \\
\text { limits }\left(\mathrm{pg} \mathrm{I}^{-1}\right)\end{array}$ & $\begin{array}{l}\text { Enhancement } \\
\text { factor }\end{array}$ & Reference \\
\hline Maleic acid grafted PTFE fibers & 22 & $0.5-1.1\left(50 \mathrm{ng} \mathrm{I}^{-1}\right)$ & $1-20$ & 69-97 & This work \\
\hline Amberlite XAD-7 + 8-HQ & 5 & $1.2-2.3\left(2 \mathrm{ng} \mathrm{I}^{-1}\right)$ & $1.5-16$ & Not available & Ref. 11 \\
\hline Iminodiacetate (IDA) based resin & 5 & 5-6 (real sample) & $20-50$ & Not available & Ref. 17 \\
\hline Muromac A-1 (IDA resin) & 8.6 & $2.5-8.9\left(1.0 \mu \mathrm{g} \mathrm{I}^{-1}\right)$ & $40-251$ & $11.1-15.6$ & Ref. 18 \\
\hline $\begin{array}{l}\text { 8-HO immobilized fluorinated metal } \\
\text { alkoxide glass }\end{array}$ & 12 & $4.7-8.0\left(10 \mathrm{ng} \mathrm{I}^{-1}\right)$ & $37-297$ & Not available & Ref. 19 \\
\hline
\end{tabular}


Table 4. Analytical results for the determination of REEs in the certified reference materials

Concentration $/ \mu \mathrm{g} \mathrm{g}^{-1}$

\begin{tabular}{|c|c|c|c|c|c|c|}
\hline \multirow[b]{2}{*}{ Element } & \multicolumn{2}{|c|}{ GBW 07312 (Sediment) } & \multicolumn{2}{|c|}{ GBW 07313 (Marine sediment) } & \multicolumn{2}{|c|}{ GBW 07405 (Soil) } \\
\hline & $\begin{array}{c}\text { Determined } \\
(\text { mean } \pm s, n=5)\end{array}$ & Certified & $\begin{array}{c}\text { Determined } \\
(\text { mean } \pm s, n=5)\end{array}$ & Certified & $\begin{array}{c}\text { Determined } \\
(\text { mean } \pm s, n=5)\end{array}$ & Certified \\
\hline La & $30.8 \pm 0.8$ & $32.7 \pm 2.2$ & $67.5 \pm 1.5$ & $67.8 \pm 5.7$ & $32.4 \pm 0.7$ & $36 \pm 6$ \\
\hline $\mathrm{Ce}$ & $56.4 \pm 1.6$ & $61 \pm 5$ & $83.4 \pm 1.7$ & $92 \pm 14$ & $96.8 \pm 1.8$ & $91 \pm 15$ \\
\hline $\operatorname{Pr}$ & $6.42 \pm 0.14$ & $6.9 \pm 1.2$ & $22.7 \pm 0.6$ & $20.1 \pm 2.5$ & $7.42 \pm 0.16$ & $7.0 \pm 1.3$ \\
\hline $\mathrm{Nd}$ & $25.3 \pm 0.5$ & $26 \pm 4$ & $86.4 \pm 2.0$ & $91.8 \pm 5.4$ & $25.5 \pm 0.7$ & $24 \pm 2$ \\
\hline $\mathrm{Sm}$ & $5.42 \pm 0.10$ & $5.0 \pm 0.5$ & $20.2 \pm 0.4$ & $21.5 \pm 2.0$ & $4.31 \pm 0.10$ & $4.0 \pm 0.6$ \\
\hline $\mathrm{Eu}$ & $0.64 \pm 0.01$ & $0.61 \pm 0.04$ & $4.74 \pm 0.12$ & $5.3 \pm 0.5$ & $0.77 \pm 0.01$ & $0.82 \pm 0.06$ \\
\hline Gd & $4.71 \pm 0.09$ & $4.4 \pm 0.4$ & $20.1 \pm 0.4$ & $22.0 \pm 1.6$ & $3.33 \pm 0.08$ & $3.5 \pm 0.3$ \\
\hline $\mathrm{Tb}$ & $0.89 \pm 0.02$ & $0.82 \pm 0.08$ & $3.42 \pm 0.06$ & $3.4 \pm 0.5$ & $0.72 \pm 0.01$ & $0.7 \pm 0.2$ \\
\hline Dy & $4.77 \pm 0.11$ & $4.8 \pm 0.2$ & $17.4 \pm 0.5$ & $19.9 \pm 2.5$ & $3.30 \pm 0.08$ & $3.7 \pm 0.6$ \\
\hline Ho & $1.02 \pm 0.02$ & $0.94 \pm 0.09$ & $4.03 \pm 0.08$ & $4.3 \pm 0.2$ & $0.91 \pm 0.02$ & $0.8 \pm 0.2$ \\
\hline $\mathrm{Er}$ & $2.91 \pm 0.06$ & $3.1 \pm 0.3$ & $10.8 \pm 0.3$ & $11.0 \pm 1.0$ & $2.33 \pm 0.04$ & $2.4 \pm 0.3$ \\
\hline Tm & $0.58 \pm 0.01$ & $0.53 \pm 0.07$ & $1.52 \pm 0.04$ & $1.54 \pm 0.17$ & $0.38 \pm 0.01$ & $0.41 \pm 0.05$ \\
\hline $\mathrm{Yb}$ & $3.91 \pm 0.06$ & $3.7 \pm 0.5$ & $10.6 \pm 0.3$ & $9.8 \pm 1.6$ & $2.74 \pm 0.07$ & $2.8 \pm 0.5$ \\
\hline Lu & $0.65 \pm 0.01$ & $0.58 \pm 0.08$ & $1.27 \pm 0.03$ & $1.46 \pm 0.28$ & $0.44 \pm 0.09$ & $0.42 \pm 0.07$ \\
\hline
\end{tabular}

the developed method and those certified indicates the accuracy of the developed methodology.

\section{Application to Natural Water Samples}

The developed method was applied to determination of (ultra)trace REE in three seawater samples and three river water samples collected locally. The recoveries of $2 \mathrm{ng} 1^{-1}$ REEs spiked in seawater samples and $10 \mathrm{ng} \mathrm{1^{-1 }}$ REEs spiked in river water samples ranged from 90 to $106 \%$. The concentration of the REEs ranged from 0.12 to $8.25 \mathrm{ng}^{-1}$ in the seawater samples and 1.26 to $243 \mathrm{ng}$ $1^{-1}$ in the river water samples. The precisions (RSD) of the concentrations of REEs are in the range 1.2 to $4.8 \%$, which are adequate for the construction of geochemically informative normalized REE patterns [27, 28]. Detailed analytical results for these water samples are supplied in the Supplementary Material section (which can be found in the electronic version of this article).

\section{Conclusions}

In summary, the developed FI on-line solid-phase extraction coupled with ICP-MS using the maleic acid grafted PTFE fibers as sorbent allows effective preconcentration and separation of REEs from $\mathrm{Ba}$ and other matrix elements, and provides a rapid, simple, automatic, selective, and highly sensitive technique for determination of (ultra)trace REEs in environmental materials. More work should be done on the applicability of the fibers for solid-phase extraction of other metal ions so that the fibers can be commercialized for wider applications in the future.

\section{Acknowledgments}

This research was supported by the National Natural Science Foundation of China (no. 20275019).

\section{References}

1. Prohaska, T.; Hann. S.; Latkoczy, C.; Stingeder, G. Determination of rare earth elements $U$ and $T h$ in environmental samples by inductively coupled plasma double focusing sector field mass spectrometry (ICPSMS). J. Anal. At. Spectrom. 1999, 14, 1-8.

2. Kramer, K. J. M.; Dorten, W. S.; Groenewoud, H. V.; Hann, E.; Kramer, G. N.; Monteiro, L.; Muntau. H.; Quevauviller, P. Collaborative study to improve the quality control of rare earth element determinations in environmental matrices. J. Environ. Monit. 1999, 1, 83-89.

3. Barretto, P. M. C.; Fujimori, K. Natural analogue studies: Geology and mineralogy of Morro do Ferro. Brazil Chem. Geol. 1986, 55, 297-312.

4. Hieftje, G. M.; Myers, D. P.; Li, G. Q.; Mahoney, P. P.; Burgoyne T. W.; Ray, . S. J.; Guzowski, J. P. Toward the next generation of atomic mass spectrometers. J. Anal. At. Spectrom. 1997, 12, 287-292.

5. Jarvies, K. E.; Gray, A. L.; Houk, R. S.; Jarvis, I; McLaren, J. W.; Williams, J. G., Eds.; Handbook of Inductively Coupled Plasma Mass Spectrometry; Blackie: New York, 1992

6. Beauchemin, D. Inductively coupled plasma mass spectrometry. Anal. Chem., 2002, 74, 2873-2894.

7. Shabani, M. B.; Akagi, T.; Masuda, A. Preconcentration of trace rareearth elements in seawater by complexation with bis(2-ethylhexyl) hydrogen phosphate and 2-ethylhexyl dihydrogen phosphate adsorbed on a C18 cartridge and determination by inductively coupled plasma mass spectrometry. Anal. Chem. 1992, 64, 737-743.

8. Humphris, S.1984; Henderson, P., Ed.; In The mobility of the rare earth elements in the crust. Rare Earth Element Geochem, Elsevier: Amsterdam, pp 317-342.

9. Albarade, F. Geochemistry, an introduction; Cambridge University Press: New York, 2004; p 248

10. Zhang, T. H.; Shan, X. Q.; Liu, R. X.; Tang, H. X.; Zhang, S. Z. Preconcentration of rare earth elements in seawater with poly(acrylaminophosphonic dithiocarbamate) chelating fiber prior to determination by inductively coupled plasma mass spectrometry. Anal. Chem. 1998, 70, 3964-3968.

11. Vicente, O.; Padro, A.; Martinez, L.; Olsina, R.; Marchevsky, E. Determination of some rare earth elements in seawater by inductively coupled plasma mass spectrometry using flow injection preconcentration. Spectrochim. Acta Part B 1998, 53, 1281-1287.

12. Dev, K.; Pathak, R.; Rao, G. N. Sorption behavior of lanthanum(III), neodymium(III), terbium(III), thorium(IV), and uranium(VI) on amberlite XAD-4 resin functionalized with bicine ligands. Talanta 1999, 48, $579-584$.

13. Inagaki, K.; Haraguchi, H. Determination of rare earth elements in human blood serum by inductively coupled plasma mass spectrometry after chelating resin preconcentration. Analyst 2000, 125, 191-196.

14. Wen, B.; Shan, X. Q.; Xu, S. G. Preconcentration of ultratrace rare earth elements in seawater with 8-hydroxyquinoline immobilized polyacrylonitrile hollow fiber membrane for determination by inductively coupled plasma mass spectrometry. Analyst 1999, 124, 621-626.

15. Kühn, M.; Kriews, M. Improved detection of transition and rare earth elements in marine samples with the CETAC DSX-100 preconcentration/matrix elimination system and ICP-MS. Fresenius J. Anal. Chem. 2000, 367, 440-444.

16. Prasada Rao, T; Kala, R. On-line and off-line preconcentration of trace and ultratrace amounts of lanthanides. Talanta 2004, 63, 949-959. 
17. Willie, S. N.; Sturgeon, R. E. Determination of transition and rare earth elements in seawater by flow injection inductively coupled plasma timeof-flight mass spectrometry. Spectrochim. Acta Part B 2001, 56, 1707-1716.

18. Hirata, S.; Kajiya, T.; Aihara, M.; Honda, K.; Shikino, O. Determination of rare earth elements in seawater by on-line column preconcentration inductively coupled plasma mass spectrometry. Talanta 2002, 58, 1185-1194

19. Kajiya, T.; Aihara, M.; Hirata, S. Determination of rare earth elements in seawater by inductively coupled plasma mass spectrometry with online column pre-concentration using 8-quinolinole-immobilized fluorinated metal alkoxide glass. Spectrochim. Acta Part B 2004, 59, 543-550.

20. Wang, J. H.; Hansen, E. H. On-line sample pretreatment schemes for trace-level determinations of metals by coupling flow injection or sequential injection with ICP-MS. Trends Anal. Chem. 2003, 22, 836-846.

21. Fang, Z.-L. Flow Injection Separation and Preconcentration; VCH: Weinheim, 1993, p 98.

22. Wang, Z.-H.; Zhang, Z.-P.; Wang, Z.-P.; Liu, L.-W.; Yan, X.-P. Acrylic acid grafted polytetrafluoroethylene fiber as a new packing for flow injection on-line microcolumn preconcentration coupled with flame atomic absorption spectrometry for determination of lead and cadmium in environmental and biological samples. Anal. Chim. Acta 2004, 514, 149-155.
23. Chen, W.; Neoh, K. G.; Kang, E. T.; Tan, K. L.; Liaw, D. J.; Huang, C. C. Surface modification and adhesion characteristics of polycarbonate films after graft copolymerization. J. Polym. Sci. 1998, 36, 357-366.

24. Oshima, A.; Seguchi, T.; Tabata, Y. ESR study on free radicals trapped in crosslinked polytetrafluoroethylene (PTFE). II. Radical formation and reactivity. Radiat. Phys. Chem. 1999, 55, 61-71.

25. Weltje, L.; Heidenreich, H.; Zhu, W.; Wolterbeek, H. T.; Korhammer, S. Lanthanide concentrations in freshwater plants and mollusks related to those in surface water, pore water, and sediment. A case study in the Netherlands. Sci. Total Environ. 2002, 286, 191-214.

26. Wang, X.-R.; Barnes, R. M. Chelating resins for on-line flow injection preconcentration with inductively coupled plasma atomic emission spectrometry. J. Anal. Atom. Spectrom. 1989, 4, 509-518.

27. Esser, B. K.; Volpe, A.; Kenneally, J. M.; Smith, D. K. Preconcentration and purification of rare earth elements in natural waters using silica immobilized 8-hydroxyquinoline and a supported organophosphorus extractant. Anal. Chem. 1994, 66, 1736-1742.

28. Aggarwal, J. K.; Shabani, M. B.; Palmer, M. R.; Ragnarsdottir, K. V. Determination of the rare earth elements in aqueous samples at sub-ppt levels by inductively coupled plasma spectrometry and flow injection ICP-MS. Anal. Chem. 1996, 68, 4418-4423. 